\title{
Rice Leaf Transcriptional Profiling Suggests a Functional Interplay Between Xanthomonas oryzae pv. oryzae Lipopolysaccharide and Extracellular Polysaccharide in Modulation of Defense Responses During Infection
}

\author{
Anil Madhusoodana Girija, Bipin Kumar Kinathi, Mylavarapu B. Madhavi, Palaparthi Ramesh, \\ Sridivya Vungarala, Hitendra Kumar Patel, and Ramesh V. Sonti
}

CSIR-Centre for Cellular and Molecular Biology, Uppal Road, Hyderabad 500007, India

Accepted 2 December 2016.

\begin{abstract}
Treatment of rice leaves with isolated Xanthomonas oryzae pv. oryzae lipopolysaccharide (LPS) induces the production of callose deposits, reactive oxygen species, and enhanced resistance against subsequent bacterial infection. Expression profiling of $X$. oryzae pv. oryzae LPS-treated rice (Oryza sativa subsp. indica) leaves showed that genes involved in the biosynthetic pathways for lignins, phenylpropanoids, chorismate, phenylalanine, salicylic acid, and ethylene, as well as a number of pathogenesis-related proteins are up-regulated. Gene ontology categories like cell-wall organization, defense response, stress response, and protein phosphorylation/kinases were found to be upregulated, while genes involved in photosynthesis were down-regulated. Coinfiltration with xanthan gum, the xanthomonas extracellular polysaccharide (EPS), suppressed LPS-induced callose deposition. Gene expression analysis of rice leaves that are treated with an EPS-deficient mutant of $X$. oryzae pv. oryzae indicated that a number of defense-regulated functions are up-regulated during infection. These transcriptional responses are attenuated in rice leaves treated with an EPS-deficient mutant that is also deficient in the $\mathrm{O}$-antigen component of LPS. Overall, these results suggest that the O-antigen component of $X$. oryzae pv. oryzae LPS induces rice defense responses during infection and that these are suppressed by bacterial EPS.
\end{abstract}

Lipopolysaccharide (LPS) is an essential constituent of the outer membrane of all gram-negative bacteria. LPS is known to induce a variety of plant defense responses including a calcium influx into the cytoplasm, production of reactive oxygen species (ROS) and nitric oxide (NO), increased extracellular $\mathrm{pH}$, callose deposition, lignification of the cell wall, and the induction of pathogenesis-related (PR) genes (Erbs and Newman 2012; Silipo et al. 2010). Prior treatment with LPS has been shown to suppress the hypersensitive response (HR) that is induced by avirulent pathogens in plants (Graham et al. 1977; Newman et al. 2000). LPS isolated from a variety of bacteria

The data from this microarray experiment are submitted in the Gene Expression Omnibus repository under accession number GSE61833.

Corresponding author: R. V. Sonti; E-mail: sonti@ccmb.res.in

*The $\boldsymbol{e}$-Xtra logo stands for "electronic extra" and indicates that four supplementary figures and seven supplementary tables are published online.

C 2017 The American Phytopathological Society was also shown to elicit nitric oxide synthesis in Arabidopsis (Zeidler et al. 2004). LPS triggers an arginine-utilizing source for NO generation and the defense responses induced are dependent on NPR1, a key mediator in salicylic acid-mediated defense responses (Sun et al. 2012).

LPS is composed of lipid A, core oligosaccharide, and O-antigen. Several studies conducted in tobacco, pepper, and Arabidopsis have shown that the lipid A and core oligosaccharide components of LPS are sufficient for eliciting plant responses (Graham et al. 1977). However, the lipid A and core portions of LPS isolated from Xanthomonas axonopodis pv. citri were not capable of eliciting defense responses like callose deposition or PR gene induction in orange (Citrus sinensis) while complete LPS elicited those responses (Casabuono et al. 2011). These data indicate that the O-antigen portion of LPS also contributes to eliciting defense responses in orange. Further evidence for the role of O-antigen in inducing plant responses to LPS was provided by Bedini et al. (2005), who showed that synthetically prepared oligo rhamnans, which constitute the back bone of O-antigen portion of LPS in many phytopathogenic bacteria, could suppress HR in Arabidopsis following inoculation with an avirulent strain of Pseudomonas syringae and can induce expression of the PR-1 gene (a defense gene and marker of SA signaling pathway) (Bedini et al. 2005). Overall, these results suggest that different components of LPS, including the lipid A, core oligosaccharide, as well as the O-antigen, might be involved in inducing defense responses in plants.

Transcriptional profiling has been used to study gene expression changes in LPS-treated plant cells. In one of the first reports of LPS-induced gene expression changes in plants, microarray analysis was performed in Arabidopsis, using a custom-designed cDNA microarray of 700 defense response genes. The results revealed that LPS induces an array of defense response genes including many genes encoding PR proteins, glutathione $S$-transferases, and cytochrome P450 (Zeidler et al. 2004). In another study conducted using differential display transcript profiling, gene expression changes induced in Arabidopsis in response to intact LPS, lipid A, and O-antigen from Burkholderia cepacia were studied (Madala et al. 2012). All three treatments induced expression of defense-associated genes, but lipid A and O-antigen appear to be acting as partial agonists, as intact LPS elicited a more comprehensive set of genes. In suspension-cultured rice cells, LPS preparations from different bacterial sources, including Xanthomonas oryzae pv. oryzae (the bacterial blight pathogen of rice), were shown to induce various defense responses, like ROS generation and 
programmed cell death (PCD) (Desaki et al. 2006). The transcriptional changes induced in rice suspension-cultured cells in response to Pseudomonas aeruginosa LPS were studied, using a rice oligo-microarray containing 22,575 features. This study revealed that more than 800 genes are up-regulated and that they are associated with defense responses, signal transduction, secondary metabolism, and proteolysis as well as a number of transcription factors. The downregulated genes included those involved in cell-cycle regulation, like cyclins and expansins.

The responses of suspension-cultured rice cells to LPS may not be fully reflective of the responses that would be produced by rice cells in intact plants. Therefore, we examined the responses of rice leaves to treatment with $X$. oryzae pv. oryzae LPS. We report that treatment of rice leaves with purified LPS from $X$. oryzae pv. oryzae results in ROS production, callose deposition, and enhanced resistance against subsequent infection by the bacterium. This indicates that treatment with LPS is priming the plant defense responses. Transcriptional profiling of LPS-treated rice leaves indicates that a number of functions involved in defense responses are up-regulated while photosynthesis genes are downregulated. Prior treatment with Xanthomonas extracellular polysaccharide (EPS) suppresses LPS-induced defense responses. Transcriptional profiling reveals that treatment with an EPS-deficient $X$. oryzae pv. oryzae mutant results in differential expression of a number of defense response-associated functions and that these responses are ameliorated if the EPS-deficient mutant is also LPS-deficient.

\section{RESULTS}

\section{X. oryzae pv. oryzae LPS induces defense responses in rice leaves and roots.}

Callose deposition is considered a marker of plant innate immune response. Treatment with LPS has been reported to induce callose deposition in leaves of several plants (Erbs et al. 2010) and we wanted to determine whether $X$. oryzae pv. oryzae LPS would elicit a similar response in rice leaves. The leaves of rice seedlings were infiltrated with $X$. oryzae pv. oryzae LPS $(100 \mu \mathrm{g} / \mathrm{ml})$ and were stained with aniline blue to identify callose deposition. The experiment was replicated three times and the results consistently showed increased callose deposition in LPS-treated leaves as compared with water-infiltrated controls (Fig. 1). The spots visible in the water control might be due to a wounding response.

ROS are produced in plants during a defense response (Torres et al. 2006). Infiltration of $X$. oryzae pv. oryzae LPS into leaves of rice seedlings resulted in increased ROS production compared with water-infiltrated leaves. Induction of ROS was inferred by comparing the intensity of brown-colored deposits formed in 3,3'-diaminobenzidine (DAB)-stained leaves that were infiltrated with either $X$. oryzae pv. oryzae LPS $(100 \mu \mathrm{g} / \mathrm{ml})$ or water. The leaves treated with LPS showed a more intense and significantly higher level of DAB staining as compared with the waterinfiltrated leaves (Fig. 2). The dark coloration visible in the water control might be due to a wounding response.

We then proceeded to determine whether treatment with isolated $X$. oryzae pv. oryzae LPS would enhance resistance against subsequent infection by $X$. oryzae pv. oryzae. The midveinal regions of rice leaves were first injected with either LPS or with water and, $15 \mathrm{~h}$ later, all of the leaves were inoculated with $X$. oryzae pv. oryzae. The lesion lengths were measured 14 days after inoculation. The leaves that were treated with LPS showed an average lesion length of $3.7 \mathrm{~cm}$, while the leaves treated with milliQ water exhibited an average lesion length of $13.8 \mathrm{~cm}$ (Fig. 3 ). Thus, the treatment of rice leaves with LPS resulted in a priming response and enhanced resistance toward subsequent infection with $X$. oryzae pv. oryzae.
LPS has been reported to induce PCD in rice suspension cultures (Desaki et al. 2006), and we wanted to determine whether $X$. oryzae pv. oryzae LPS would elicit a similar response in rice roots. The roots of rice seedlings were treated with $X$. oryzae pv. oryzae LPS $(100 \mu \mathrm{g} / \mathrm{ml})$ and were stained with propidium iodide (PI) (Krattinger et al. 2009) to assess the occurrence of PCD. The results from three replications consistently showed a PCD-like response (PI internalization in the cells of rice roots) in LPS-treated roots as compared with waterinfiltrated controls (Supplementary Fig. S1).

\section{Transcriptional profiling to identify \\ LPS-induced gene expression changes in rice leaves.}

In order to identify the genes induced in rice leaves following treatment with $X$. oryzae pv. oryzae LPS, a transcriptome profiling was performed using the Affymetrix rice GeneChip genome array (containing probe sets for 51,279 rice transcripts), as described below. The analysis of transcriptome profiling using the PLIER (probe logarithmic intensity error [Affymetrix 2005]) algorithm suggested a total of 2,691 genes were differentially expressed with $>1.5$-fold change at $P<0.05$, of which 1,677 genes were up-regulated and 1,014 genes were down-regulated (Supplementary Table S1). There were 677 differentially expressed genes with greater than twofold change in expression at $P<0.05$, of which 504 genes were up-regulated and 173 genes were down-regulated. The data from this microarray experiment are submitted in the Gene Expression Omnibus repository under accession number GSE61832. The change in expression of five randomly selected upregulated genes (Os01g11860, Os06g20960, Os03g48540, Os08g41290, and Os08g10290) and five randomly selected downregulated genes (Os09g24530, Os12g38170, Os01g73540, Os08g39370, and Os12g31460) were further validated through real time quantitative polymerase chain reaction (qPCR) (Supplementary Fig. S2). In addition, the expression of three defense-related genes (peroxidase Os06g35520, peroxidase Os01g73200, and PR10 Os12g36830), whose expression is upregulated following LPS treatment, was also validated through real time qPCR (Supplementary Fig. S3).

The differentially expressed genes ( $>1.5$-fold) were analyzed using the AGRIGO SAGE (serial analysis of gene set enrichment) online tool to identify the Gene Ontology (GO) categories (gene sets) that were enriched to a statistically significant level $(P$ value $<0.05)$ by LPS treatment. The upregulated genes were found to be enriched in $217 \mathrm{GO}$ categories, whereas the downregulated genes were found to be enriched in $68 \mathrm{GO}$ categories (Supplementary Table S2). The differentially regulated genes were also analyzed using the rice pathway analysis software RiceCyc (Jaiswal et al. 2006). The results showed that metabolic pathways involved in the biosynthesis of chorismate, phenylalanine, phenylpropanoid, suberin, ethylene, and salicylic acid biosynthesis were up-regulated (Supplementary Fig. S4). Overall, these results suggest that LPS treatment results in increased expression of genes involved in the synthesis of a number of defense-related compounds. Analysis of $>1.5$-fold differentially expressed genes, using MAPMAN software (Thimm et al. 2004), indicated that LPS treatment results in increased expression of genes involved in cell functions such as translation machinery, signaling and regulation, biotic stress, vesicle transport, nuclear transport, transport, and posttranslational protein modifications, while genes involved in RNA synthesis were down-regulated (Fig. 4).

Since biotic stress-related functions are of particular relevance in this study, we used MAPMAN to identify the differentially expressed genes that are related to biotic stress (Supplementary Table S3). MAPMAN analysis suggested that several biotic stress-related functions such as genes encoding for functions 
A

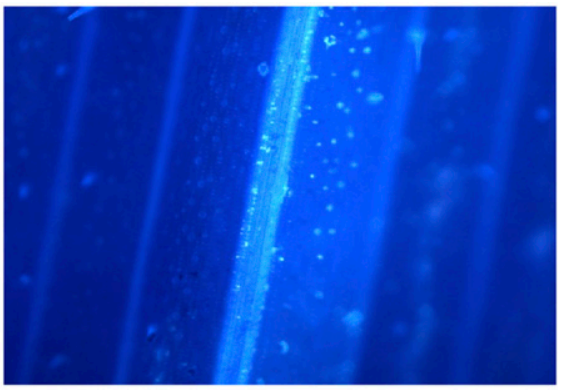

LPS $(100 \mu \mathrm{g} / \mathrm{ml})$

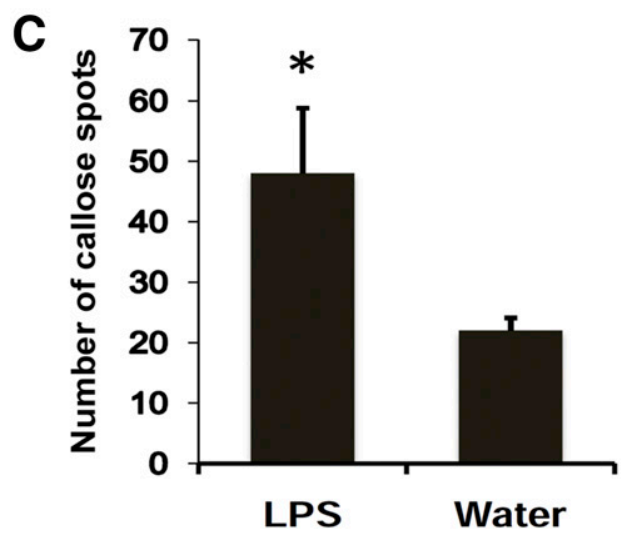

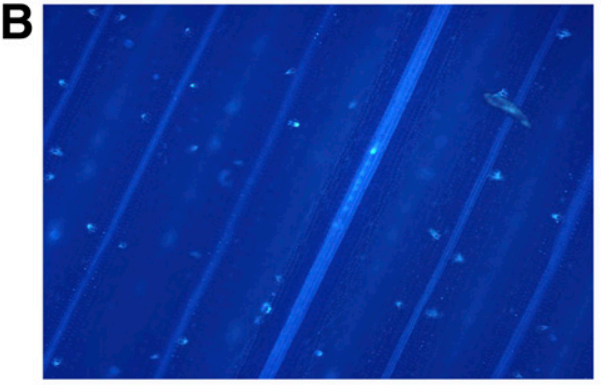

Water

Fig. 1. Treatment with Xanthomonas oryzae pv. oryzae lipopolysaccharide (LPS) induces callose deposition in rice leaves. Rice leaves that were infiltrated with either $100 \mu \mathrm{g}$ of X. oryzae pv. oryzae LPS per milliliter or water were stained with aniline blue and were examined under an epifluorescence microscope (with $10 \times$ zoom). The bright spots in these pictures indicate callose deposits. The number of callose spots obtained A, after LPS infiltration was found to be significantly higher than B, the water treated leaves. C, Plot of the average number of callose spots per $0.5 \mathrm{~cm}^{2}$ from three leaves. Bars represent standard deviations. Student $t$-test was performed and was found to be significant with $P<0.05$ (indicated by an asterisk). Similar results were obtained in three independent experiments.

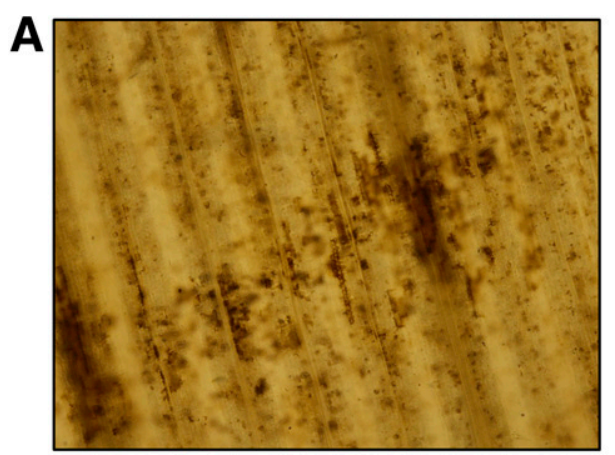

LPS $(100 \mu \mathrm{g} / \mathrm{ml})$

C

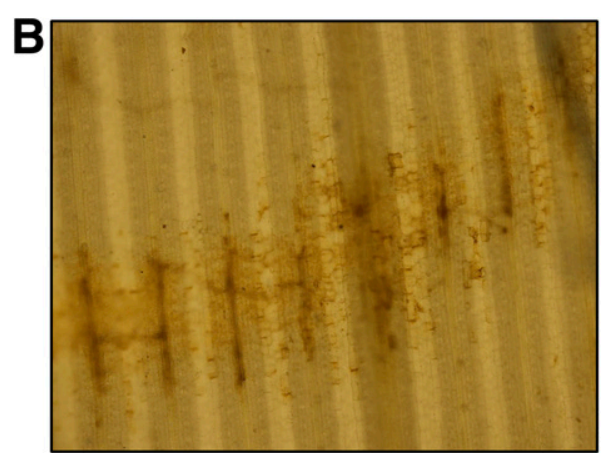

Water

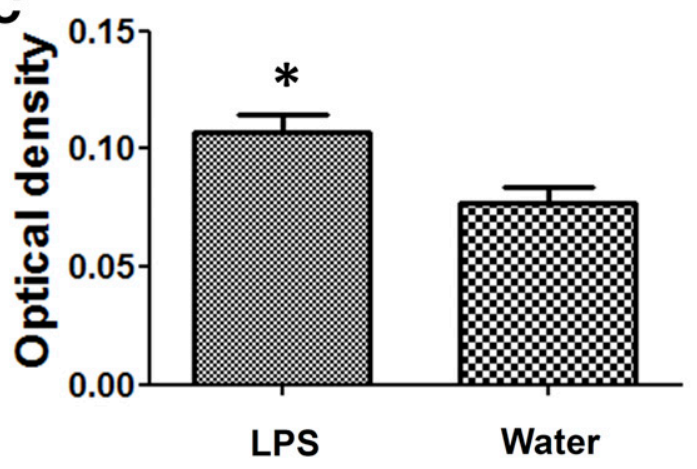

Samples

Fig. 2. Treatment of rice leaves with Xanthomonas oryzae pv. oryzae lipopolysaccharide (LPS) induces production of reactive oxygen species (ROS). Rice leaves were infiltrated with either A, X. oryzae pv. oryzae LPS $(100 \mu \mathrm{g} / \mathrm{ml})$ or B, water and were immersed in DAB (3,3'-diaminobenzidine) staining solution. The increased level of dark brown coloration in LPS-treated leaves compared with water-treated leaves indicates increased ROS production upon LPS treatment. Similar results were obtained in four independent experiments. C, The levels of ROS generated (intensity of DAB staining; optical density) was quantitated using an image analysis tool and was found to be significantly different at $P<0.05$ (indicated by an asterisk). 
in cell-wall alteration and strengthening, peroxidases, glycosyl transferases, cytochrome $\mathrm{P} 450$, beta glucanases, heat-shock proteins, receptor kinases, protein degradation, secondary metabolism, amino acid metabolism, and transcription factors were differentially expressed upon treatment with LPS. Several genes involved in photosynthesis and others involved in terpene synthesis were found to be downregulated upon LPS treatment.

Genes involved in cell-wall synthesis, modification, and degradation were found to be differentially expressed upon LPS treatment. Two cellulose synthase genes (LOC_Os02g49332, LOC_Os06g02180) and three hemicellulose synthase genes (LOC_Os03g05110, LOC_Os07g09670, LOC_Os02g52560) were up-regulated, while two other cellulose synthase genes were down-regulated (LOC_Os03g26044, LOC_Os09g30120). Cell wall-degrading enzymes like pectate lyases and cellulases were also found to be upregulated. Genes coding for proteins related to cell-wall strengthening, like arabinogalactan proteins, glycine-rich cell-wall structural proteins, proline-rich cell-wall structural proteins, and laccases (enzymes involved in lignification and strengthening of the cell wall) were also found to be upregulated more than threefold by LPS treatment. Inhibitors of cell wall-degrading enzymes like pectin methyl esterase inhibitor and pectin lyase inhibitor protein were also found to be upregulated upon LPS treatment. These results indicate that LPS treatment induces the strengthening and remodeling of the plant cell wall.

Peroxidases are known to be directly or indirectly involved in several defense-related functions, such as production of ROS and an oxidative burst, polymerization of cell-wall compounds, production of phytoalexins (Almagro et al. 2009). A total of 24 different peroxidase genes were found to be upregulated, while only one was down-regulated. The expression of a number of PR proteins was also up-regulated (23 genes at more than threefold) following LPS treatment (Table 1). These included three PR-2 proteins (beta glucanases), eight PR-3 proteins (chitinases), ten PR-9 proteins (Class-III peroxidases), and two PR-10 proteins (ribonucleases).

A number of transcription factors that are known to respond to stress responses are differentially expressed after LPS treatment. Ten MYB transcription factor genes are up-regulated and one is down-regulated, while eight AP2 transcription factor genes were found to be upregulated and two downregulated upon LPS treatment. An AP2/B3 transcription factor coding gene (LOC_Os01g04800.1) that was 7.6 fold upregulated was the highest upregulated transcription factor, upon LPS treatment. WRKY transcription factor genes are known to be key players in plant immune responses, acting as both positive and negative regulators, and seven WRKY transcription factors were found to be upregulated, while four of them were downregulated after LPS treatment.

Several receptor kinases serve as pattern recognition receptors for microbe-associated molecular patterns (MAMPs) (Boller and Felix 2009). LPS treatment in rice resulted in the upregulation of 96 receptor-like kinase genes, while only two were down-regulated. OsSERK2 (LOC_Os04g38480), a coreceptor essential for the function of the three rice immune receptors Xa3, Xa21, and OsFLS2 (Chen et al. 2014), was found to be twofold upregulated upon LPS treatment. We queried the rice kinase database (Jung et al. 2010) to identify the interacting partners for the receptor kinase proteins that are up-regulated upon LPS treatment. The interacting partners of eight differentially expressed receptor kinase genes were identified from this database (Supplementary Table S4).

Among the list of differentially expressed genes, about 186 genes coding for ribosomal proteins were differentially expressed upon LPS treatment, of which 150 were up-regulated while 36 were down-regulated. Differential expression of ribosomal protein genes in plant cells undergoing a resistance response has been reported (Mysore et al. 2003). Differential expression of ribosomal protein genes has been suggested to serve as a modulator of gene expression within cells (Komili et al. 2007).

Transcriptional profiling of rice leaves infected with either wild type or surface polysaccharide-deficient $X$. oryzae pv. oryzae strains.

In order to assess the role of LPS in inducing immune responses during infection, we wanted to compare gene expression changes in rice leaves infected with either wild-type $X$. oryzae pv. oryzae (BXO43) or an LPS-deficient mutant (BXO1003). The BXO1003 carries a Tn5 insertion in the $\mathrm{O}$-antigen biosynthetic gene cluster

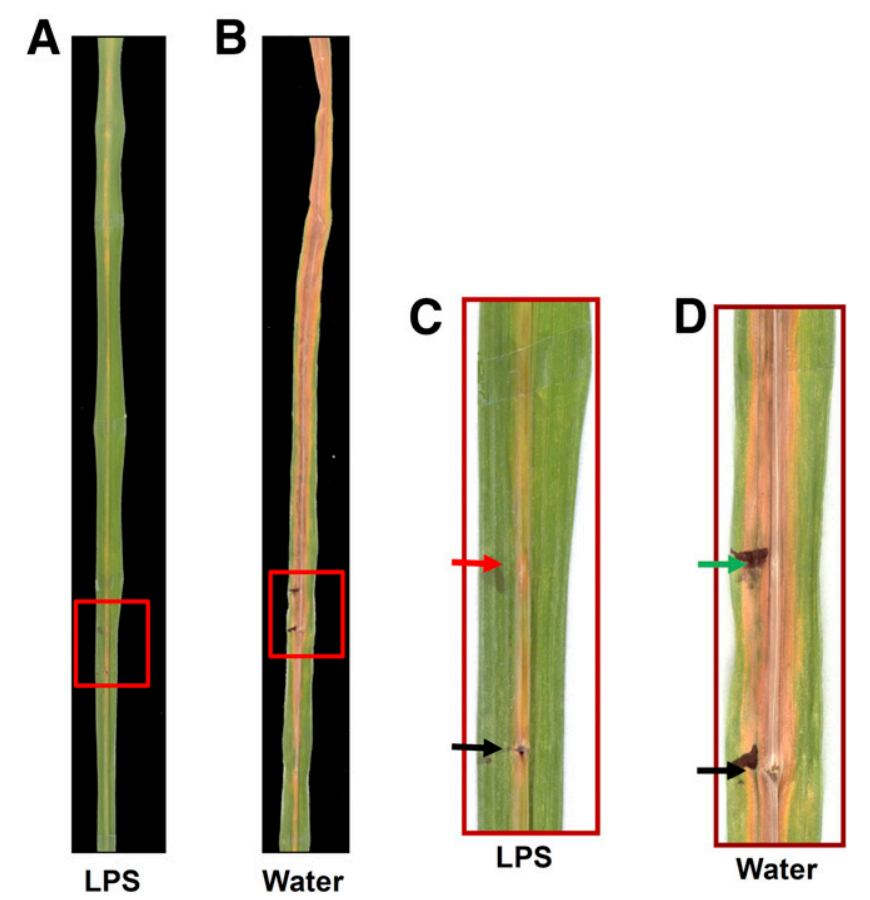

E

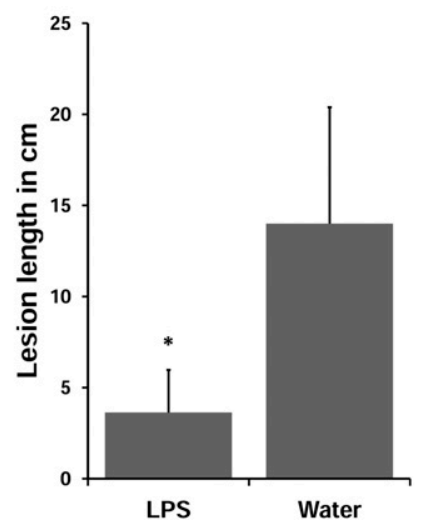

Fig. 3. Treatment of the midveinal regions of rice leaves with Xanthomonas oryzae pv. oryzae lipopolysaccharide (LPS) induces resistance against subsequent bacterial infection. The midveinal regions of rice leaves were pretreated with either A, X. oryzae pv. oryzae LPS $(100 \mu \mathrm{g} / \mathrm{ml})$ or $\mathbf{B}$, water. After $15 \mathrm{~h}$, wild-type $X$. oryzae pv. oryzae (strain BXO43) was inoculated 2 to $3 \mathrm{~cm}$ below the point of pretreatment. $\mathbf{C}$ and $\mathbf{D}$, enlargment of the boxed regions in $\mathrm{A}$ and $\mathrm{B}$, respectively. The upper arrows indicate the position of injection of either LPS (C) or water (D), while the lower arrows indicate the point of $X$. oryzae pv. oryzae inoculation. Leaves pretreated with LPS showed marked reduction in lesion formation compared with water pretreated leaves. E, Plot showing the average lesion lengths obtained 14 days after inoculation. Bars indicate standard deviation. Student $t$-test was performed and was found to be significant with $P<0.05$ (indicated by an asterisk). 
and the strain is deficient in the O-antigen component of LPS (Dharmapuri et al. 2001). However, since the mutation in the gene for O-antigen production also makes the cell deficient in EPS production, we also assessed gene expression changes in rice leaves infected with a strain that is EPS-deficient but LPS-proficient (BXO1002) (Dharmapuri and Sonti 1999). The BXO1002 and BXO1003 strains are known to be deficient for virulence on the rice cultivar Taichung Native-1, which is susceptible to BXO43 (Dharmapuri and Sonti 1999; Dharmapuri et al. 2001). At $15 \mathrm{~h}$ after inoculation, we found 800 rice genes that are differentially expressed ( $>1.5$ fold with $P<0.05$ ) (718 up- and 82 downregulated) following infection with wild-type $X$. oryzae pv. oryzae, 1,660 genes (1,225 up- and 435 downregulated) following infection with BXO1002, and 1,248 genes (995 up- and 253 downregulated) following infection with BXO1003. The expression data were validated using real time PCR for three defense-related genes, (peroxidase [Os06g35520], peroxidase [Os01g73200], and PR-10 [Os12g36830]) that are overexpressed in all three treatments.

SAGE was done to identify statistically significant enrichment (false discovery rate adjusted $P$ value $<0.05$ ) of GO categories that are differentially expressed in rice following inoculation with the three $X$. oryzae pv. oryzae strains. Among the differentially expressed genes, a total of 1,542, 1,137, and 725 genes belonging to treatments with BXO1002, BXO1003, and BXO43, respectively, could be assigned to at least one GO category (Supplementary Table S5). Overall, there is a reduction in the number of GO functional groups that are enriched after treatment with BXO1003 (90 up- and 40 downregulated) and BXO43 (116 up- and 19 downregulated) when compared with BXO1002 (156 up- and 74 downregulated) treatment. Even within the GO categories that are commonly up-regulated by treatment with all three strains, the number of genes that are up-regulated by

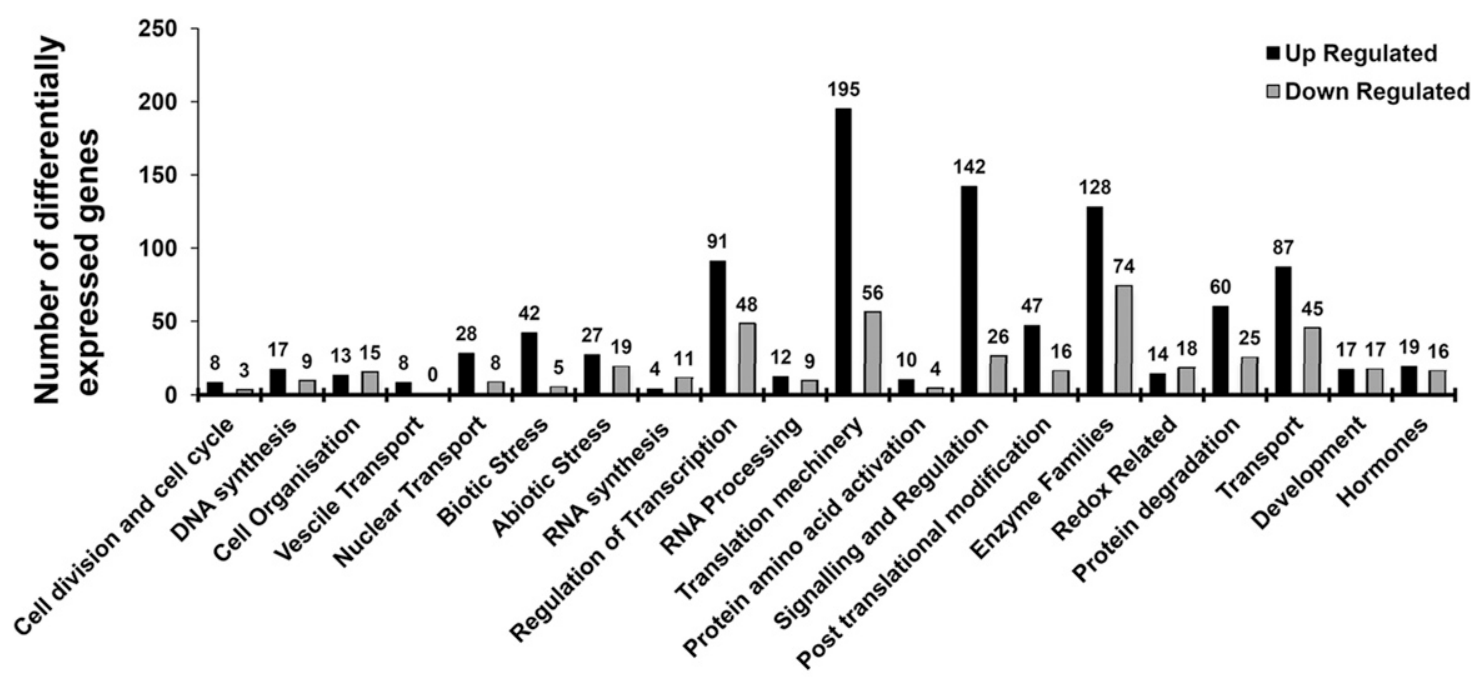

Functional categories

Fig. 4. Cellular functions that are differentially expressed in rice upon lipopolysaccharide (LPS) treatment. Differentially expressed genes belonging to various cellular functions were categorized, using MAPMAN software. Black boxes represent the number of upregulated genes within a cell function category, while white boxes represent the number of downregulated genes in that category. Numbers above the boxes indicate the numbers of genes that are either up- or down-regulated.

Table 1. Pathogenesis related proteins that are more than threefold upregulated upon lipopolysaccharide treatment

\begin{tabular}{|c|c|c|c|}
\hline Spot no. & LOCUS ID & Fold change & Blast $\mathrm{X} / \mathrm{BlasN}$ description \\
\hline 1 & LOC_Os06g35520.1 & 17.48 & Class III peroxidase (PR-9) \\
\hline 2 & LOC_Os01g73200.1 & 15.87 & Class III peroxidase (PR-9) \\
\hline 3 & LOC_Os11g37960.1 & 10 & Chitinase (PR-3) \\
\hline 4 & LOC_Os12g36830.1 & 8 & PR-10 \\
\hline 5 & LOC_Os01g22249.1 & 7.3 & Class III peroxidase (PR-9) \\
\hline 6 & LOC_Os03g 13210.1 & 7.2 & Class III peroxidase (PR-9) \\
\hline 7 & LOC_Os07g35560.1 & 6.3 & $\beta-1,3$-Glucanase (PR-2) \\
\hline 8 & LOC_Os01g71340.1 & 5.8 & $\beta-1,3$-Glucanase (PR-2) \\
\hline 9 & LOC_Os04g59150.1 & 5.7 & Class III peroxidase (PR-9) \\
\hline 10 & LOC_Os02g39330.1 & 5.2 & Chitinase (PR-3) \\
\hline 11 & LOC_Os01g51570.1 & 4.8 & $\beta-1,3$-Glucanase (PR-2) \\
\hline 12 & LOC_Os10g28050.1 & 4.7 & Chitinase (PR-3) \\
\hline 13 & LOC_Os12g36860.1 & 4.65 & PR-10 \\
\hline 14 & LOC_Os06g32990.1 & 4.6 & Class III peroxidase (PR-9) \\
\hline 15 & LOC_Os07g47990 & 4.57 & Class III peroxidase (PR-9) \\
\hline 16 & LOC_Os01g64100.1 & 4.18 & Chitinase (PR-3) \\
\hline 17 & LOC_Os07g48010.1 & 4.16 & Class III peroxidase (PR-9) \\
\hline 18 & LOC_Os10g39680.1 & 3.9 & Chitinase (PR-3) \\
\hline 19 & LOC Os01g47070.1 & 3.9 & Chitinase (PR-3) \\
\hline 20 & LOC_Os07g48020.1 & 3.72 & Class III peroxidase (PR-9) \\
\hline 21 & LOC_Os01g64110.1 & 3.7 & Chitinase (PR-3) \\
\hline 22 & LOC_Os11g47600.1 & 3.7 & Chitinase (PR-3) \\
\hline 23 & LOC_Os01g73190.1 & 3 & Class III peroxidase (PR-9) \\
\hline
\end{tabular}


treatment with BXO1002 is significantly higher as compared with treatment with either BXO1003 or BXO43.

The GO categories related to alkaloid biosynthetic process, coumarin metabolic process, lignin biosynthetic process, chorismate metabolic process, and peroxidase reaction represent some defense-related functions that were enriched among the upregulated categories after treatment with BXO1002. Several of these GO categories, such as chorismate metabolic process and peroxidase reaction, are also up-regulated by BXO1003 and BXO43. Lignin biosynthesis appears to be represented in the upregulated category after treatment with either BXO1002 or BXO1003. However, other categories such as alkaloid biosynthesis and coumarin biosynthesis are only represented in the upregulated category after treatment with BXO1002. Overall, treatment with BXO1002 appears to elicit a more comprehensive response as compared with treatment with either BXO1003 or BXO43. Also, as was observed after LPS treatment, functions related to photosynthesis are down-regulated in all three treatments.

A comparison was made of the rice genes that are differentially expressed after treatment with the three $X$. oryzae pv. oryzae strains with those that are differentially expressed after treatment with LPS. This comparison indicates that about $70 \%$ of the genes that are differentially expressed after treatment with any of the $X$. oryzae pv. oryzae strains, i.e., BXO1002, BXO1003, and BXO43, were also differentially expressed after LPS treatment (Fig. 5; Supplementary Table S6). This suggests a high degree of overlap in rice defense responses that are elicited by these treatments. The rice gene-expression changes induced after treatment with different $X$. oryzae pv. oryzae strains showed a Pearson correlation coefficient of $>0.9$ among themselves and a correlation coefficient of 0.84 toward LPS treatment.

A heat map visualization of rice gene expression profiles after treatment with BXO1002, BXO1003, and BXO43, using the software Multi Experiment Viewer v. 4.8 (Howe et al. 2010), showed that gene expression changes were highest, both in number and magnitude, for BXO1002. These changes were significantly attenuated in the treatment with BXO1003, while treatment with wild-type BXO43 showed the lowest response (Fig. 6A). A separate heat map of genes involved in biotic stress, prepared using MAPMAN and visualized using Multi Experiment Viewer v. 4.8, indicates that genes involved in secondary metabolite biosynthesis, signaling, peroxidases, and transcription factors are induced to a greater extent upon treatment with BXO1002 as compared with treatment with BXO1003 (Fig. $6 \mathrm{~B})$. Overall, the transcriptome data suggests that treatment with the BXO1002 mutant induces a more comprehensive response as compared with treatment with the other two strains.

Prior treatment with the BXO1002 mutant induces resistance against subsequent infection by wild-type $X$. oryzae pv. oryzae in rice. The gene expression changes that are induced by the BXO1002 mutant in rice leaves suggested that prior treatment with this mutant might provide enhanced resistance against subsequent $X$. oryzae pv. oryzae infection. To test this possibility, rice leaves were treated with either the BXO1002 strain or with water and subsequently inoculated with the BXO43 strain. The results indicate that rice leaves treated with BXO1002 and subsequently infected with BXO43 exhibited reduced lesions, as compared with control rice leaves that were mock-inoculated with water and subsequently infected with BXO43 (Fig. 7). Interestingly, the rice leaves that are pretreated with the BXO1003 strain also exhibit reduced lesions upon subsequent inoculation with $\mathrm{BXO} 43$. This indicates that, although the BXO1003 strain induces substantially ameliorated gene expression changes in rice leaves as compared with

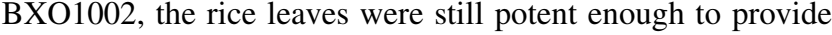
enhanced resistance compared with the control leaves that were treated with water.

Xanthomonas EPS suppresses LPS-induced callose deposition. Either xanthan gum $(10 \mathrm{mg} / \mathrm{ml})$, a commercially available EPS from Xanthomonas sp., or water was first infiltrated into leaves of tobacco plants. One hour later, $X$. oryzae pv. oryzae LPS $(100 \mu \mathrm{g} / \mathrm{ml})$ was infiltrated into the same leaf regions; $15 \mathrm{~h}$ later, these leaves were stained for callose deposition. Tobacco leaves that were pretreated with EPS showed less callose deposition compared with the water-pretreated leaves, indicating that prior treatment with EPS suppresses LPS-induced callose deposition (Fig. 8). It is pertinent to note that this effect of the pretreatment is observed even if the gap between treatment and pretreatment is only by $1 \mathrm{~h}$.

\section{DISCUSSION}

The results presented in this study indicate that treatment with $X$. oryzae pv. oryzae LPS induces callose deposition and ROS in young rice leaves and also enhances resistance against subsequent $X$. oryzae pv. oryzae infection in mature rice leaves. Transcriptional profiling of rice leaves using an Affymetrix rice

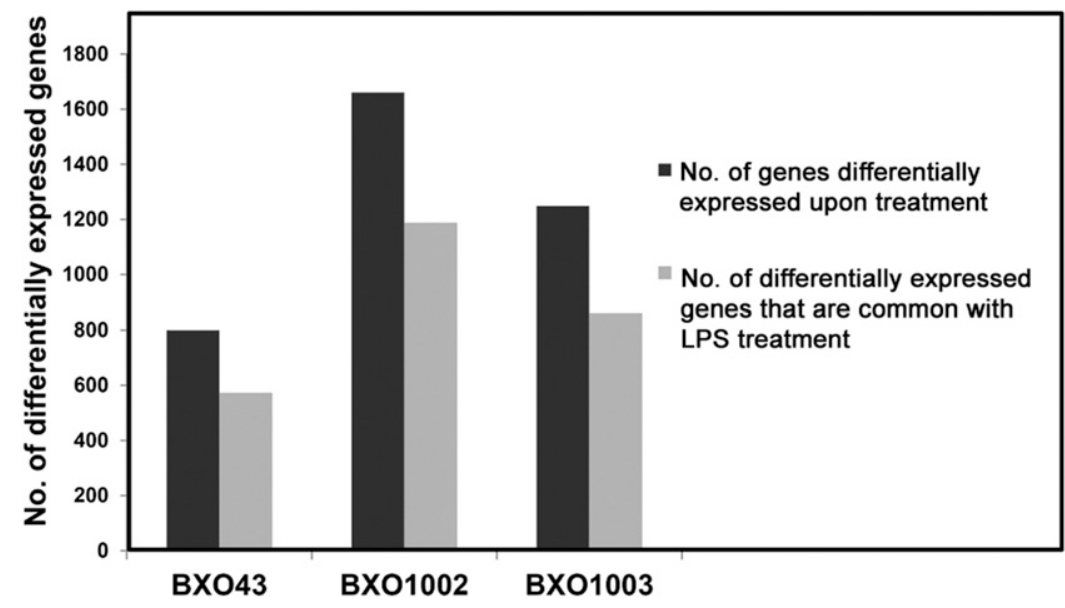

Fig. 5. Similarity in the rice transcriptional response following treatment with either Xanthomonas oryzae pv. oryzae lipopolysaccharide (LPS) or different Xanthomonas strains. About $70 \%$ of the genes that are differentially expressed upon treatment with wild-type strain X. oryzae pv. oryzae BXO43 or with mutant $X$. oryzae pv. oryzae strains BXO1002 and BXO1003 are also differentially expressed upon treatment with X. oryzae pv. oryzae LPS. 
A

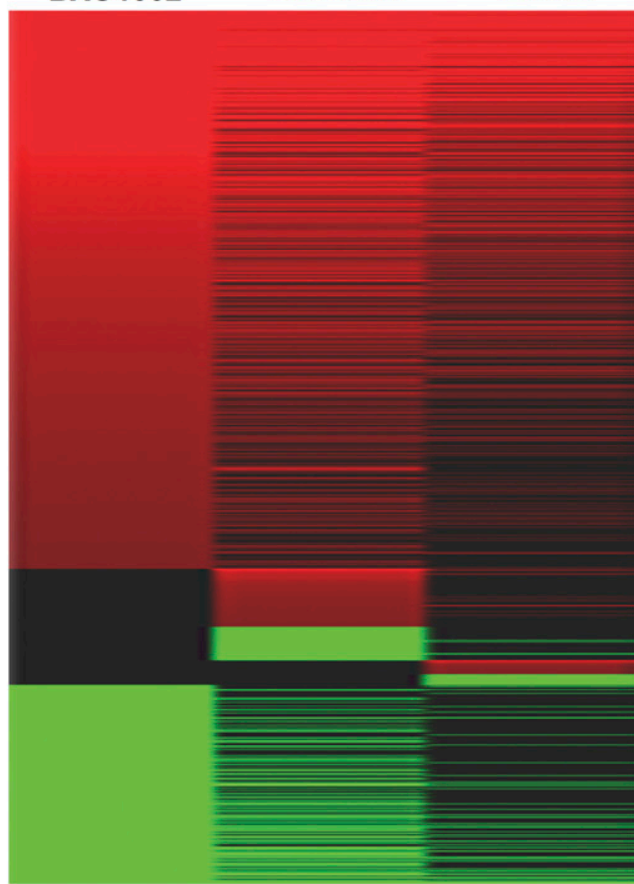

$+3$

B

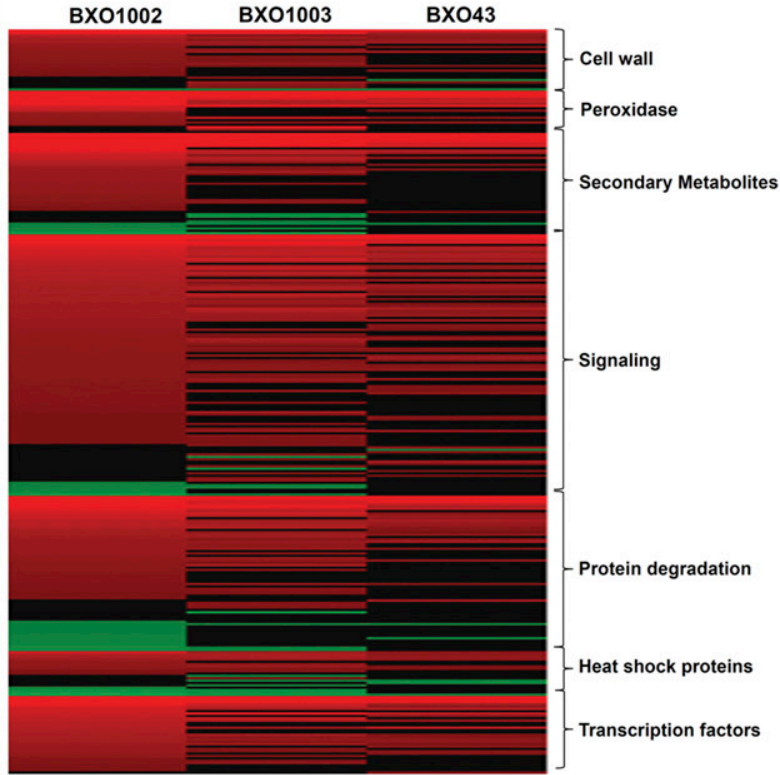

$+4$

Fig. 6. Treatment of rice leaves with an extracellular polysaccharide (EPS) and lipopolysaccharide (LPS)-deficient Xanthomonas oryzae pv. oryzae strain induces an attenuated transcriptional response as compared with treatment with a strain that is EPS-deficient but LPS-proficient. BXO $43=$ wild-type $X$. oryzae pv. oryzae; BXO 1002 = EPS-deficient but LPS-proficient $X$. oryzae pv. oryzae strain; $\mathrm{BXO} 1003=X$. oryzae pv. oryzae strain deficient in both EPS and LPS. A, Heat map representing expression levels of rice genes that are $>1.5$-fold differentially expressed after treatment with BXO1002,

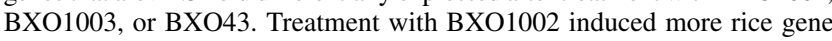
expression changes than did treatment with BXO1003. Treatment with either BXO1002 or BXO1003 induced more rice gene expression changes than did treatment with $\mathrm{BXO} 43$. B, Heat map representing expression levels of biotic stress-related rice genes that are $>1.5$-fold differentially expressed after treatment with BXO1002, BXO1003, or BXO43. MAPMAN software was used to identify the category of biotic stress related genes from the total list of differentially expressed genes.
GeneChip array revealed that LPS treatment results in significant changes in gene expression, with about 2,691 genes being differentially expressed.

Genes involved in cell-wall organization and biogenesis, peroxidase reaction, protein phosphorylation, and iron and calcium binding were found to be enriched among the upregulated genes, while genes involved in photosynthesis-related functions were

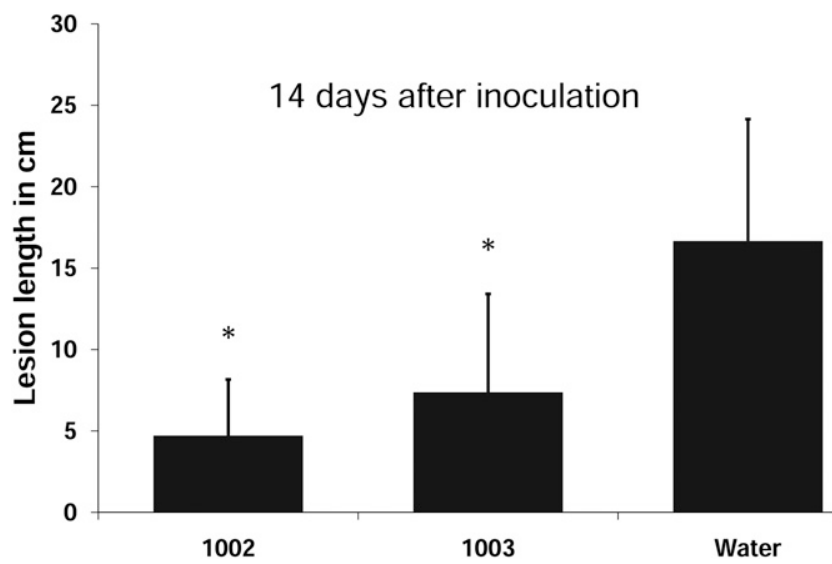

Fig. 7. Prior treatment with extracellular polysaccharide (EPS)-deficient mutants induces resistance in rice against subsequent infection with wild-type Xanthomonas oryzae pv. oryzae. The midveinal regions of rice leaves were pretreated with either BXO1003 (EPS ${ }^{-}$, LPS $^{-}$[lipopolysaccharide-deficient]), BXO1002 (EPS ${ }^{-}, \mathrm{LPS}^{+}$), or water. After 15 h, wild-type $X$. oryzae pv. oryzae (BXO43) was inoculated 2 to $3 \mathrm{~cm}$ below the point of pretreatment. The lesion lengths were measured 14 days after inoculation. Lesions that are formed on rice leaves that have been pretreated with either BXO1002 or BXO1003 are significantly smaller (Student $t$-test with significance $P<0.05$ ) as compared with lesions in control leaves that were pretreated with water. A total of 10 to 15 leaves were inoculated per experiment, and similar results were obtained in three independent experiments.
A

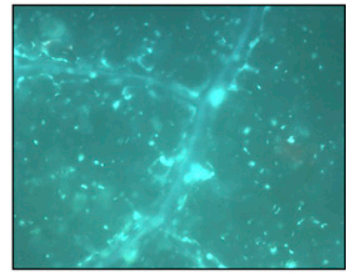

LPS
$\mathbf{B}$

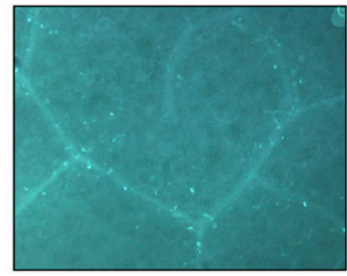

LPS + EPS

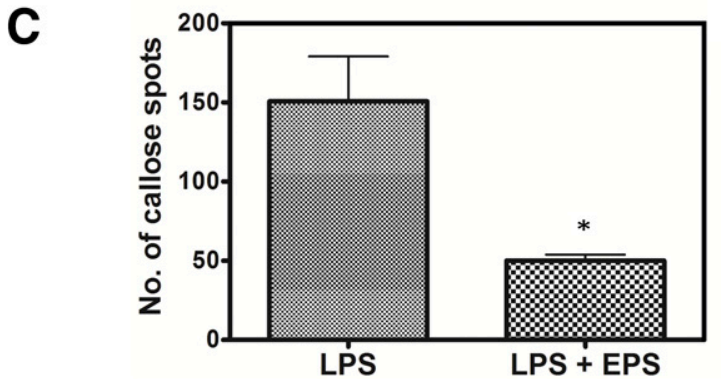

Fig. 8. Xanthomonas extracellular polysaccharide (EPS) suppresses lipopolysaccharide (LPS) induced callose deposition. Either A, water or B, EPS (xanthan gum, $10 \mathrm{mg} / \mathrm{ml}$ ) was infiltrated into tobacco leaves. The infiltrated area was subsequently again infiltrated with LPS $(100 \mu \mathrm{g} / \mathrm{ml})$ and was stained with aniline blue. C, Leaves pretreated with EPS showed significantly reduced callose deposition as compared with leaves pretreated with water. In each experiment, five leaves were used for each treatment. Similar results were obtained in three independent experiments. 
found to be enriched among the downregulated genes. Genes encoding functions involved in the metabolic pathways for biosynthesis of chorismate and phenyl propanoids are also upregulated. Chorismate is a precursor for biosynthesis of the plant defense hormone salicylic acid and indole alkaloids, while phenyl propanoids are important precursors of structural polymers like lignins and suberins. More than 20 different PR proteins, including 10 different peroxidases, were also up-regulated upon LPS treatment. Peroxidases are known to play multiple roles in plant defense responses against bacterial pathogens, like reinforcement of cell-wall physical barriers comprising lignin, suberin, feruloylated polysaccharides, and hydroxyproline-rich glycoproteins, enhanced production of ROS, and enhanced production of phytoalexin (Hiraga et al. 2001). A respiratory burst oxidase homolog protein $\mathrm{F}$ (RbohF) (LOC_Os08g35210) was up-regulated 3.3-fold upon LPS treatment. RbohF proteins are calcium-dependent NADPH oxidases that are known to generate ROS during incompatible plant-pathogen interactions (Sagi and Fluhr 2006). Five different ATP binding cassette transporters annotated as pleotropic drug resistance proteins were found to be upregulated upon LPS treatment. Lr34, an ATP binding cassette transporter in wheat, is known to function as a resistance gene imparting durable and broad spectrum resistance toward fungal pathogens (Krattinger et al. 2009). Taken together, these changes can lead to the enhanced resistance that is conferred by LPS treatment against subsequent $X$. oryzae pv. oryzae infection.

A lectin receptor kinase, LOC_Os07g38810, is 2.4-fold upregulated upon LPS treatment and was found to interact in yeast two-hybrid assays with a vesicle tethering family protein and a homolog of SHR5, which is another lectin receptor kinase (LOC_Os08g10290) (Jung et al. 2010). The SHR5 homolog is sixfold up-regulated upon LPS treatment. It exhibits homology (75\% identity, $99 \%$ query coverage, E value 0 ) to the sugarcane SHR5 containing extracellular leucine-rich repeats, a malectin binding domain, and an intracellular kinase domain. The downregulation of SHR5 is essential for the symbiotic association between sugarcane and a nitrogen-fixing endophytic bacterium (Vinagre et al. 2006). It is possible that SHR5 might be involved in recognizing a bacterial MAMP and mounting a defense response; hence, its downregulation might have become essential for symbiotic association between sugarcane and bacteria.

LPS was shown to be taken inside the cytoplasm through possible receptor-mediated endocytosis (Gross et al. 2004). The association of LOC_Os07g38810 coded protein with a vesicletethering protein indicates the possibility that this receptor might be associated with endocytotic vesicles. Although speculative, it is possible that the proteins coded by LOC_Os07g38810 and LOC_Os08g10290 might constitute a heterodimer involved in functioning as a LPS receptor in rice and this can be further tested by coimmunoprecipitation and bimolecular fluorescence complementation.

Genes involved in photosynthetic functions were downregulated upon LPS treatment. The downregulation of expression of photosynthetic functions following exposure of plants to biotic stresses has been reported previously and is thought to help in temporarily diverting energy as well as nitrogen and carbon resources to meet the immediate demands of mounting a defense response (Bilgin et al. 2010). Interestingly, genes involved in terpene biosynthesis were also found to be downregulated upon LPS treatment. This appears paradoxical, as terpenes are involved in plant defense responses. However, the downregulation of the terpene biosynthetic pathway following LPS treatment might reflect the possibility that these molecules provide protection against herbivores and might not be useful in the context of a microbial infection.

Interestingly about $70 \%$ of the genes that were differentially expressed upon treatment with different $X$. oryzae pv. oryzae strains were also differentially expressed following LPS treatment. Most of the defense-related genes and the metabolic pathways that are up-regulated and GO classes that are enriched upon treatment with $X$. oryzae pv. oryzae mutants were the same as those that were observed after treatment with $X$. oryzae pv. oryzae LPS. In the treatment with $X$. oryzae pv. oryzae strains, the rice cells might be getting exposed to numerous MAMPs of bacterial origin, including LPS. It is possible that the signaling pathway downstream of different bacterial MAMP receptors might be converging and triggering defense responses of a similar nature. Thus, the rice response in terms of gene expression changes toward a cocktail of MAMPs need not be drastically different from the rice response toward individual MAMPs.

In gram-negative bacteria such as $X$. oryzae pv. oryzae, LPS is an essential constituent of the outer membrane. How does $X$. oryzae pv. oryzae manage to cause disease if LPS induces such potent defense responses? In this work, purified xanthan, the purified and commercially available exopolysaccaride from Xanthomonas spp. was able to suppress callose deposition induced by LPS. This suggests the possibility that EPS might be acting as a suppressor of LPS-induced innate immune responses during $X$. oryzae pv. oryzae infection of rice. Previously, it has been reported that the suppression of callose deposition by xanthan is important for the infectivity of Xanthomonas campestris pv. campestris on Arabidopsis and $\mathrm{Ni}$ cotiana benthamiana (Yun et al. 2006). Also, it has been shown that xanthan is able to suppress MAMP-triggered immunity by chelating divalent calcium ions, an important signaling molecule in plant immune responses (Aslam et al. 2008).

Treatment of rice leaves with an EPS-deficient mutant (BXO1002) induces resistance against subsequent infection by wild-type $X$. oryzae pv. oryzae. An analysis of the gene expression changes that are induced by the EPS-deficient mutant in rice leaves also indicates that this strain is an inducer of rice defense responses (a priming response). This presumably occurs because BXO1002 is proficient in production of elicitors (such as LPS, flagellin, cell wall-degrading enzymes) of plant innate immune responses but is defective in suppression of these immune responses.

Transcriptional profiling of rice leaves revealed that infection with the BXO1002 (an X. oryzae pv. oryzae mutant deficient in EPS biosynthesis but proficient in LPS production) and BXO1003 (an X. oryzae pv. oryzae mutant deficient in both O-antigen LPS and EPS biosynthesis) strains causes greater changes, both in the number of differentially expressed genes and in the level of expression of these genes, when compared with the treatment with wild-type BXO43. The enhanced ability of the mutant $X$. oryzae pv. oryzae strains to induce gene expression changes in rice, as compared with wild-type $X$. oryzae pv. oryzae, can be attributed to the lack of EPS in the mutants. EPS may be acting as a suppressor of plant defense responses and the lack of it in the mutant strains might be triggering higher rice defense responses and gene expression changes, as compared with the wild-type $X$. oryzae pv. oryzae strain. However, there is a clear difference in the gene expression changes induced by the BXO1002 and BXO1003 strains in rice. BXO1003 was attenuated in its ability to induce rice gene expression changes as compared with $\mathrm{BXO1002}$. This could be attributed to the lack of $\mathrm{O}$-antigen in $\mathrm{BXO1003.} \mathrm{These}$ results indicate that the $\mathrm{O}$-antigen component of $X$. oryzae $\mathrm{pv}$. oryzae LPS is being recognized by the host innate immune system during growth of the pathogen in rice.

Although the transcriptional profiling results indicate that the $\mathrm{O}$-antigen-deficient mutant BXO1003 is attenuated in its ability to induce defense gene expression, treatment of rice leaves with this strain could trigger induced resistance toward subsequent $X$. oryzae pv. oryzae inoculation. This indicates 
that, although the gene expression changes that are induced by the BXO1003 mutant are attenuated compared with those induced by BXO1002, they are still sufficient to confer a resistance response. In the absence of the O-antigen, how might the BXO1003 mutant induce rice defense responses? This might be either because of the presence of other MAMPs, such as flagellin, or that the residual components of LPS in the O-antigen-deficient BXO1003 mutant, namely, lipid A and core oligosaccharide, are also capable of inducing rice defense responses. The lipid A and core oligosaccharide constituents of LPS are known to induce plant defense responses (Silipo et al. 2005; Zeidler et al. 2004).

The BXO1002 and BXO1003 mutants are not observed to induce callose deposits any more than the wild-type BXO43 strain when infiltrated into rice leaves (unpublished data). However, these strains can induce differential expression of a number of defense genes as well as strong resistance against subsequent infection of $X$. oryzae pv. oryzae. The inability of the BXO1002 and BXO1003 strains to induce callose deposition in rice leaves may be due to the fact that they have a functional type 3 secretion system (T3SS), which secretes effectors known to suppress rice basal defense responses such as callose deposition (Jha et al. 2007; Sinha et al. 2013). We postulate that, although the T3SS effectors are able to suppress callose deposition, they are not able to suppress other defense responses such as changes in expression of defense genes that are induced in the absence of EPS.

It has been previously reported that there is a lot of variability in O-antigen biosynthetic gene clusters among different xanthomonads and also between different $X$. oryzae pv. oryzae strains (Patil and Sonti 2004; Patil et al. 2007). These gene clusters vary from each other with respect to their sizes and gene content as well as gene sequence and the variation is likely to result in the presentation of very different O-antigens on the bacterial cell surface. Similar variation in animal pathogenic bacteria has been attributed to help in evasion of the host innate immune system. It would be interesting to determine if different xanthomonas $\mathrm{O}$-antigens induce different responses in plants, as this might contribute a selection pressure to maintain strains with different $\mathrm{O}$-antigen clusters among the xanthomonads.

In summary, the results presented here indicate that treatment of rice leaves with $X$. oryzae pv. oryzae LPS induces substantial gene expression changes that can contribute to resistance against subsequent $X$. oryzae pv. oryzae infection. Transcriptional profiling with surface polysaccharide-deficient mutants indicates that the O-antigen component of the LPS serves as a MAMP during xanthomonas infection of rice. The data further suggest that xanthomonas EPS contributes to suppression of LPS-induced defense responses. Future work should be directed toward understanding the rice functions, including the receptors, signaling components, and transcription factors that are involved in induction of LPS-elicited defense responses and to determine the manner in which the xanthomonas EPS suppresses these defense responses.

\section{MATERIALS AND METHODS}

\section{Preparation of Xanthomonas cultures.}

$X$. oryzae pv. oryzae strains $\mathrm{BXO} 43$ (wild-type $X$. oryzae pv. oryzae), BXO1002 (gumG::Tn5 mutant that is deficient in EPS biosynthesis), and BXO1003 (wxoB::Tn5 mutant that is defective in LPS and EPS) were streaked out on peptone sucrose agar plates from glycerol stocks. Single colonies were inoculated in $3 \mathrm{ml}$ of peptone sucrose broth and were incubated at $28^{\circ} \mathrm{C}$ for $48 \mathrm{~h} ; 10 \mu \mathrm{l}$ of this culture was used to inoculate $10 \mathrm{ml}$ of peptone sucrose broth in a conical flask and was incubated for $48 \mathrm{~h}$. The cells were pelleted by centrifuging at 5,000 $\times g$, were resuspended in $10 \mathrm{ml}$ of sterile milliQ water, and were pelleted again by centrifugation. The pellets were resuspended again in $10 \mathrm{ml}$ of milliQ water and the optical density at $600 \mathrm{~nm}$ $\left(\mathrm{OD}_{600}\right)$ was measured using a spectrophotometer. The $\mathrm{OD}_{600}$ was adjusted to 0.8 for all the cultures.

\section{Isolation of $X$. oryzae pv. oryzae LPS.}

$X$. oryzae pv. oryzae $\mathrm{BXO} 43$ was inoculated into conical flasks containing peptone sucrose medium and was incubated at $28^{\circ} \mathrm{C}$ for $36 \mathrm{~h}$. The bacterial cells were pelleted by centrifugation at 5,000 $\times \mathrm{g}$ for $20 \mathrm{~min}$. Pellets (approximately $60 \mathrm{~g}$ wet weight) were resuspended in $0.9 \% \mathrm{NaCl}$ (wt/vol), centrifuged again and resuspended in milliQ water. LPS was extracted using the hot phenol water method with the following modifications (Westphal and Jann 1965). The water phase was dialyzed (molecular weight cutoff of 14,000) extensively against milliQ water to remove traces of phenol. Proteins and nucleic acids were removed by treatment of the dialysate with, per milliliter, $100 \mu \mathrm{g}$ of DNAse I, $15 \mu \mathrm{g}$ of RNAse, and $150 \mu \mathrm{g}$ of proteinase $\mathrm{K}$. The solution was dialyzed again and was lyophilized. Finally, the LPS was resuspended and purified by ultra-high speed centrifugation at $19,000 \times g$ at $4^{\circ} \mathrm{C}$ for $2 \mathrm{~h}$. The pellet was lyophilized, weighed, and dissolved in milliQ water. to obtain an LPS solution of $100 \mu \mathrm{g} / \mathrm{ml}$.

To prepare a LPS-free control solution, $4 \mathrm{ml}$ of $100-\mu \mathrm{g} / \mathrm{ml}$ $X$. oryzae pv. oryzae LPS was diluted 100 fold by adding milliQ water to make $400 \mathrm{ml}$ of $1-\mu \mathrm{g} / \mathrm{ml} X$. oryzae pv. oryzae LPS solution, and $1 \mathrm{ml}$ of $1-\mu \mathrm{g} / \mathrm{ml} X$. oryzae pv. oryzae LPS was passed through Detoxi-gel endotoxin removing columns (Thermo Scientific) with $1 \mathrm{ml}$ of resin containing immobilized polymyxin B, to bind and remove LPS from the solution. The flow-through from the column was collected, the column was regenerated using 1\% deoxycholate solution, and the column was subsequently washed multiple times with milliQ water to remove traces of deoxycholate solution. Each column was reused multiple (four to five) times. About $300 \mathrm{ml}$ of flowthrough was concentrated to $3 \mathrm{ml}$ using a vacuum centrifuge, and this served as the control solution for LPS treatment.

\section{Aniline blue staining for callose deposition.}

Either $50 \mu \mathrm{l}$ of $100-\mu \mathrm{g} / \mathrm{ml}$ X. oryzae pv. oryzae LPS or milliQ water was infiltrated into the adaxial surfaces of leaves of 10-day-old rice seedlings, using a 1-ml needleless syringe. After $15 \mathrm{~h}, 1.5-\mathrm{cm}-$ long pieces containing the infiltrated region were cut from the leaves. The leaf pieces were incubated in absolute alcohol for $5 \mathrm{~min}$ at $55^{\circ} \mathrm{C}$, to remove the chlorophyll, followed by incubation in $70 \%$ alcohol and $50 \%$ alcohol and water wash. The de-chlorophyllated leaf pieces were incubated in $0.01 \%$ (wt/vol) aniline blue stain for about $2 \mathrm{~h}$, followed by water wash. The aniline blue-stained leaves were then mounted on a glass slide with $50 \%$ glycerol and were observed in an Axioplan-2 upright epifluorescence microscope with blue filter at an objective magnification of $10 \times$ (excitation wavelength, $365 \mathrm{~nm}$ and emission wavelength, above $420 \mathrm{~nm}$ long pass). Callose deposits were seen as bluish green spots. Photos of the infiltrated area were taken and the callose spots in each field of observation were counted. Each experiment consisted of three LPS-infiltrated leaves and three milliQ water-infiltrated leaves. The experiments were repeated three times. In the assay for suppression of LPSinduced callose deposition by EPS, leaves of 7- to 8-week-old tobacco (Nicotiana tabacum) plants were infiltrated with either $200 \mu \mathrm{l}$ of $10-\mathrm{mg} / \mathrm{ml}$ xanthan gum (Sigma-Aldrich) or $200 \mu \mathrm{l}$ of milliQ water. An hour later, the same leaf regions were infiltrated with $X$. oryzae pv. oryzae LPS $(100 \mu \mathrm{g} / \mathrm{ml})$ and, $15 \mathrm{~h}$ later, the infiltrated region was stained with aniline blue and was visualized as described above. 


\section{3,3' -diaminobenzidine (DAB) staining assay for $\mathrm{ROS}$ and its quantification.}

Detection of ROS (hydrogen peroxide) by DAB staining in rice leaves was performed as reported by Daudi and O'Brien with modifications mentioned below (Daudi and O'Brien 2012). $50 \mu \mathrm{l}$ of $100 \mu \mathrm{g} / \mathrm{ml}$ X. oryzae pv. oryzae LPS and sterile MQ water were infiltrated separately into the adaxial surface of leaves of 10 days old rice seedlings (one leaf/seedling) using a $1 \mathrm{ml}$ needleless syringe. Four hours after infiltration, the infiltrated regions of leaves were cut and were immersed in $5 \mathrm{ml}$ of freshly prepared DAB staining solution $(50 \mathrm{mg} / \mathrm{ml} \mathrm{DAB}$, Tween 20 (0.05\% vol/vol), $\left.10 \mathrm{mM} \mathrm{Na}{ }_{2} \mathrm{HPO}_{4}, \mathrm{pH} 3.0\right)$ in $50-\mathrm{ml}$ propylene tubes, were covered with aluminum foil, and were incubated for $8 \mathrm{~h}$, under shaking conditions $(100 \mathrm{rpm})$ at room temperature. Following incubation, the aluminum foil was removed and the DAB staining solution was replaced with $40 \mathrm{ml}$ of bleaching solution (ethanol/acetic acid/glycerol in a ratio of $3: 1: 1$ ). Tubes were incubated at $95^{\circ} \mathrm{C}$ for $15 \mathrm{~min}$. This step was repeated three to four times to remove all the chlorophyll of leaves. The photographs were taken in white light illumination under a simple microscope. The oxidized form of DAB forms a brown precipitate in the leaves. The levels of ROS generated (intensity of DAB staining) were further quantified by the image analysis tool ImageJ. DAB-stained leaf images were converted to grayscale and were uploaded to the ImageJ tool for measurement of the units of intensity (mean gray value). For a similar size of images for LPS and water treatment, max intensity and mean intensity were calculated and, finally, OD values were obtained with the following formula for both the samples: $\mathrm{OD}=\log$ (max intensity/mean intensity). Average OD values with standard deviation obtained from four independent leaves for LPS and MQ treatments were plotted on a graph using GraphPad Prism 5, and a student $t$ test $(P<0.05)$ was performed to test the level of significance.

\section{Local induced-resistance assay.}

Either $200 \mu \mathrm{l}$ of $100-\mu \mathrm{g} / \mathrm{ml}$ X. oryzae pv. oryzae LPS or an equal volume of milliQ water was injected into the midveinal regions in leaves of 40-day-old rice plants, using a 1-ml syringe, and, $15 \mathrm{~h}$ later, the midveins were inoculated by pricking on the midvein at a point about $2 \mathrm{~cm}$ below the point of injection, using a needle dipped in a colony of wild-type $X$. oryzae pv. oryzae. The lesion lengths were measured 14 days after inoculation. Cultures of $X$. oryzae pv. oryzae strains resuspended in milliQ water to an $\mathrm{OD}_{600}$ of 0.8 were used in induced-resistance assays in which, instead of LPS, the initial inoculations were done with either the BXO1002 or BXO1003 $X$. oryzae pv. oryzae strains.

\section{Sample preparation for microarray analysis.}

Greenhouse-grown (with $12 \mathrm{~h}$ of light and $12 \mathrm{~h}$ of dark) 40day-old rice plants were used for these experiments. Leaves from plants in a single pot were either injected with $200 \mu \mathrm{l}$ of $100-\mu \mathrm{g} / \mathrm{ml}$ X. oryzae pv. oryzae LPS or $200 \mu \mathrm{l}$ of control solution. In sample preparations following bacterial treatment, the leaves were injected with $200 \mu \mathrm{l}$ of BXO1002, BXO1003, BXO43 bacterial cultures or milliQ water. Treatments were performed in triplicate, injections were made into the midveins of five leaves, and then, $15 \mathrm{~h}$ after injection, 4-cm-long portions of midveins were cut out from below the point of injection and were flash frozen in liquid nitrogen.

\section{RNA isolation.}

RNA was isolated using the Trizol (Life Technologies) reagent, following the manufacturer's protocol. About $20 \mathrm{mg}$ of the treated midvein tissue was homogenized, using a pestle and mortar, in the presence of $2 \mathrm{ml}$ of Trizol solution and was incubated for $5 \mathrm{~min}$, followed by centrifugation at $12,000 \times g$ for $10 \mathrm{~min}$ at $4^{\circ} \mathrm{C}$. Subsequently, $400 \mu \mathrm{l}$ of chloroform was added and the mixture was shaken vigorously and was incubated for $5 \mathrm{~min}$ at room temperature. The sample was centrifuged again at $12,000 \times g$ for $15 \mathrm{~min}$ at $4^{\circ} \mathrm{C}$, and the aqueous phase was transferred to a fresh tube. Isopropanol $(1 \mathrm{ml})$ was added, the mixture was shaken vigorously for $10 \mathrm{~s}$ and was incubated for $10 \mathrm{~min}$ at room temperature. This was followed by centrifugation at $12,000 \times g$ for $8 \mathrm{~min}$ at $4^{\circ} \mathrm{C}$. The supernatant was discarded after centrifugation, the pellet was washed in $1 \mathrm{ml}$ of $75 \%$ ethanol, and the RNA pellet was dried and dissolved in milliQ water.

\section{Whole genome transcriptome profiling of rice using Affymetrix rice gene expression chips.}

The Affymetrix rice GeneChips that were used in this study were built in 2004 . However, these are still very valuable tools, as they include probe sets for 51,279 rice transcripts and cover a very significant portion of the rice genome.

cDNA preparation. The purity of isolated RNA was checked by measuring absorbance at $260 \mathrm{~nm}\left(\mathrm{~A}_{260}\right)$ and $280 \mathrm{~nm}$. $\mathrm{A}_{260}$ to $\mathrm{A}_{280}$ was in the range of 1.8 and 2 for the isolated RNA samples. The integrity of RNA was checked by separating about $2 \mu \mathrm{g}$ of RNA in denaturing agarose gel electrophoresis and visualizing by ethidium bromide staining. The RNA resolved into discrete ribosomal (r)RNA bands with the 28S rRNA showing approximately double the intensity of $18 \mathrm{~S}$ rRNA. RNA (250 ng) was used as the starting material in cDNA preparation. First-strand cDNA synthesis was done using the components of the GeneChip in vitro transcription (IVT) express kit (Affymetrix), using the manufacturer's protocol. In short, $5 \mu \mathrm{l}$ of reverse transcription enzyme buffer mix was mixed with an equal volume containing $250 \mathrm{ng}$ of total RNA and was incubated at $42^{\circ} \mathrm{C}$ for $2 \mathrm{~h}$. Second-strand synthesis was done by adding $20 \mu \mathrm{l}$ of a mix containing DNA polymerase, oligo dT, and second-strand synthesis buffer to $10 \mu \mathrm{l}$ of firststrand cDNA, mixing thoroughly, and incubating at $16^{\circ} \mathrm{C}$ for $1 \mathrm{~h}$, followed by $10 \mathrm{~min}$ at $65^{\circ} \mathrm{C}$.

IVT, biotin labeling, hybridization, and scanning. IVT master mix $(30 \mu \mathrm{l})$ containing IVT biotin-labeled uridine trinucleotide, IVT labeling buffer, and IVT enzyme was mixed thoroughly with $30 \mu \mathrm{l}$ of double-stranded cDNA sample and was incubated at $40^{\circ} \mathrm{C}$ for $4 \mathrm{~h}$ to obtain antisense RNA (aRNA). Prepared aRNA was mixed with aRNA binding beads and the aRNA was purified using a magnetic stand. The pellets were further washed using $100 \mu \mathrm{l}$ of aRNA wash solution. The purified aRNA was eluted from the RNA binding beads by adding $50 \mu \mathrm{l}$ of aRNA elution solution, followed by capturing the RNA binding beads, using a magnetic stand, and transferring the supernatant. The aRNA yield was determined by measuring the $\mathrm{A}_{260}$ value, using a NanoDrop spectrophotometer (Thermo Scientific), and an aRNA yield in the range of 40 to $60 \mu \mathrm{g}$ was obtained. The aRNA was fragmented, using a proprietary enzyme buffer mix provided in the IVT express kit. The fragmented aRNA was electrophoresed on an agarose gel to verify that the bulk of aRNA has a size of approximately $100 \mathrm{nu}-$ cleotides. The hybridization of fragmented and labeled aRNA with the rice GeneChip array (Affymetrix) was done, according to the manufacturer's protocol, at $45^{\circ} \mathrm{C}$ for $16 \mathrm{~h}$ in a hybridization oven. The GeneChips were later washed and stained using Affymetrix GeneChip Fluidics station 450, according to the manufacturer's protocol. The stained GeneChips were later scanned using the Affymetrix GeneChip Scanner to obtain the DAT file, which contains the optical image of the hybridized chip in TIFF format, which was then processed, using the GeneChip operating software, to obtain the CEL files, which contain the light-intensity information corresponding 
to each probe location in the GeneChip. CEL files are further processed along with the CDF (chip description file) to obtain the TXT file, which contains the expression values of each probe set.

Data normalization. The CEL files were uploaded into GENESPRING (Agilent Technologies) software for further analysis. The CEL files of control solution-treated samples were grouped together as the control, while the CEL files obtained from LPStreated samples were grouped together as treatment. The milliQtreated samples were grouped together as control and the data from leaves treated with Xanthomonas spp. in triplicates were considered as three separate treatments. The data were normalized using the PLIER algorithm and were subjected to differential expression analysis. The genes that are $>1.5$-fold up- or downregulated with respect to the control, with a $P$ value $<0.05$, were selected.

\section{SAGE analysis of gene expression data.}

GO was assigned to the differentially expressed genes using the AGRIGO online tool. SAGE analysis of the differentially expressed genes was performed to identify the significantly (false rate adjusted $P$ value $<0.05$ ) enriched GO terms in the treatment samples, using the SAGE module of AGRIGO online tool with default settings.

\section{Pathway analysis of gene expression data.}

The locus IDs corresponding to the Affymetrix probe IDs of differentially expressed genes were uploaded into the RiceCyc version 3.3 pathway analysis online software tool to identify the metabolic pathways that are differentially regulated upon different treatments. MapMan software was used to categorize the differentially expressed genes to different biological processes and functions and also to identify genes related to biotic stress conditions, using the respective software options (Thimm et al. 2004).

\section{Real time qPCR.}

Primers were designed to amplify about 60- to 150-bp-long sequences of 14 genes (Supplementary Table S7). The RNA samples isolated for the purpose of microarray were used as the starting material. RNA $(1 \mu \mathrm{g})$ was treated with $1 \mathrm{U}$ of DNase (New England Biolabs) and was incubated at $37^{\circ} \mathrm{C}$ for $1 \mathrm{~h}$, followed by incubation at $75^{\circ} \mathrm{C}$ for $10 \mathrm{~min}$ to deactivate the enzyme. The Dnase-treated RNA samples were used to prepare cDNA, using Superscript III reverse transcription and oligo dT primer, following the manufacturer's protocol (Life Technologies). The cDNA was diluted 20-fold and was used for real time qPCR, using VeriQuest Fast SYBR Green qPCR master mix (Affymetrix). Normalization of expression data were done using expression of the rice ubiquitin5 (AK061988) gene. Relative quantification was done based on the respective control samples, i.e., control solution-treated samples for LPS treatment and milliQ-treated samples for $X$. oryzae pv. oryzae treatments. The fold expression change with respect to the control samples were calculated based on the formula Relative fold change $=2^{-\Delta \Delta \mathrm{Ct}}$.

\section{ACKNOWLEDGMENTS}

This work was supported by grants to R. V. Sonti from the Plant-Microbe and Soil Interactions project of the Council of Scientific and Industrial Research (CSIR), the AMAAS project of the Indian Council of Agricultural Research and the Department of Biotechnology, government of India. A. M. Girija and K. B. Kumar acknowledge fellowships from the CSIR and the University Grants Commission, respectively. R. V. Sonti is also supported by a JC Bose fellowship from the Department of Science and Technology, Government of India.

\section{LITERATURE CITED}

Affymetrix. 2005. Guide to probe logarithmic intensity error (PLIER) estimation. Technical note. Affymetrix, Inc., Santa Clara, CA, U.S.A.
Almagro, L., Ros, L. G., Belchi-Navarro, S., Bru, R., Barceló, A. R., and Pedreño, M. 2009. Class III peroxidases in plant defence reactions. J. Exp. Bot. 60:377-390.

Aslam, S. N., Newman, M.-A., Erbs, G., Morrissey, K. L., Chinchilla, D., Boller, T., Jensen, T. T., De Castro, C., Ierano, T., and Molinaro, A. 2008 Bacterial polysaccharides suppress induced innate immunity by calcium chelation. Curr. Biol. 18:1078-1083.

Bedini, E., De Castro, C., Erbs, G., Mangoni, L., Dow, J. M., Newman, M. A., Parrilli, M., and Unverzagt, C. 2005. Structure-dependent modulation of a pathogen response in plants by synthetic O-antigen polysaccharides. J. Am. Chem. Soc. 127:2414-2416.

Bilgin, D.D., Zavala, J.A., Zhu, J., Clough, S.J., Ort, D.R., and DeLucia, E. 2010. Biotic stress globally downregulates photosynthesis genes. Plant Cell Environ. 33:1597-1613.

Boller, T., and Felix, G. 2009. A renaissance of elicitors: Perception of microbe-associated molecular patterns and danger signals by patternrecognition receptors. Annu. Rev. Plant Biol. 60:379-406.

Casabuono, A., Petrocelli, S., Ottado, J., Orellano, E. G., and Couto, A. S 2011. Structural analysis and involvement in plant innate immunity of Xanthomonas axonopodis pv. citri lipopolysaccharide. J. Biol. Chem. 286:25628-25643.

Chen, X., Zuo, S., Schwessinger, B., Chern, M., Canlas, P. E., Ruan, D., Zhou, X., Wang, J., Daudi, A., and Petzold, C. J. 2014. An XA21associated kinase (OsSERK2) regulates immunity mediated by the XA21 and XA3 immune receptors. Mol. Plant 7:874-892.

Daudi, A., and O'Brien, J. A. 2012. Detection of hydrogen peroxide by DAB staining in Arabidopsis leaves. Bio Protoc. 2:263.

Desaki, Y., Miya, A., Venkatesh, B., Tsuyumu, S., Yamane, H., Kaku, H., Minami, E., and Shibuya, N. 2006. Bacterial lipopolysaccharides induce defense responses associated with programmed cell death in rice cells Plant Cell Physiol. 47:1530-1540.

Dharmapuri, S., and Sonti, R. V. 1999. A transposon insertion in the gumG homologue of Xanthomonas oryzae pv. oryzae causes loss of extracellular polysaccharide production and virulence. FEMS Microbiol. Lett. 179:53-59.

Dharmapuri, S., Yashitola, J., Vishnupriya, M., and Sonti, R. V. 2001. Novel genomic locus with atypical $\mathrm{G}+\mathrm{C}$ content that is required for extracellular polysaccharide production and virulence in Xanthomonas oryzae pv. oryzae. Mol. Plant Microbe Interact. 14:1335-1339.

Erbs, G., and Newman, M.-A. 2012. The role of lipopolysaccharide and peptidoglycan, two glycosylated bacterial microbe-associated molecular patterns (MAMPs), in plant innate immunity. Mol. Plant Pathol. 13: 95-104.

Erbs, G., Molinaro, A., Dow, J. M., and Newman, M. A. 2010. Lipopolysaccharides and plant innate immunity. Subcell. Biochem. 53: 387-403.

Graham, T., Sequeira, L., and Huang, T. 1977. Bacterial lipopolysaccharides as inducers of disease resistance in tobacco. Appl. Environ. Microbiol. 34:424-432.

Gross, A., Kapp, D., Nielsen, T., and Niehaus, K. 2004. Endocytosis of Xanthomonas campestris pathovar campestris lipopolysaccharides in non host plant cells of Nicotiana tabacum. New Phytol. 165:215-226.

Hiraga, S., Sasaki, K., Ito, H., Ohashi, Y., and Matsui, H. 2001. A large family of class III plant peroxidases. Plant Cell Physiol. 42:462-468.

Howe, E., Holton, K., Nair, S., Schlauch, D., Sinha, R., and Quackenbush, J. 2010. MeV: MultiExperiment Viewer. Pages 267-277 in: Biomedical Informatics for Cancer Research. M. F. Ochs, J. T. Casagrande, and R. V. Davuluri, eds. Springer, New York.

Jaiswal, P., Ni, J., Yap, I., Ware, D., Spooner, W., Youens-Clark, K., Ren, L., Liang, C., Zhao, W., and Ratnapu, K. 2006. Gramene: A bird's eye view of cereal genomes. Nucleic Acids Res. 34:D717-D723.

Jha, G., Rajeshwari, R., and Sonti, R. V. 2007. Functional interplay between two Xanthomonas oryzae pv. oryzae secretion systems in modulating virulence on rice. Mol. Plant Microbe Interact. 20:31-40.

Jung, K.-H., Cao, P., Seo, Y.-S., Dardick, C., and Ronald, P. C. 2010. The rice kinase phylogenomics database: A guide for systematic analysis of the rice kinase super-family. Trends Plant Sci. 15:595-599.

Komili, S., Farny, N. G., Roth, F. P., and Silver, P. A. 2007. Functional specificity among ribosomal proteins regulates gene expression. Cell 131:557-571

Krattinger, S. G., Lagudah, E. S., Spielmeyer, W., Singh, R. P., HuertaEspino, J., McFadden, H., Bossolini, E., Selter, L. L., and Keller, B. 2009. A putative $A B C$ transporter confers durable resistance to multiple fungal pathogens in wheat. Science 323:1360-1363.

Madala, N. E., Molinaro, A., and Dubery, I. A. 2012. Distinct carbohydrate and lipid-based molecular patterns within lipopolysaccharides from Burkholderia cepacia contribute to defense-associated differential gene expression in Arabidopsis thaliana. Innate Immun. 18:140-154. 
Mysore, K. S., D’Ascenzo, M. D., He, X., and Martin, G. B. 2003. Overexpression of the disease resistance gene Pto in tomato induces gene expression changes similar to immune responses in human and fruitfly. Plant Physiol. 132:1901-1912.

Newman, M. A., Von Roepenack, E., Daniels, M., and Dow, M. 2000. Lipopolysaccharides and plant responses to phytopathogenic bacteria. Mol. Plant Pathol. 1:25-31.

Patil, P. B., and Sonti, R. V. 2004. Variation suggestive of horizontal gene transfer at a lipopolysaccharide (lps) biosynthetic locus in Xanthomonas oryzae pv. oryzae, the bacterial leaf blight pathogen of rice. BMC Microbiol. 4:40.

Patil, P. B., Bogdanove, A. J., and Sonti, R. V. 2007. The role of horizontal transfer in the evolution of a highly variable lipopolysaccharide biosynthesis locus in xanthomonads that infect rice, citrus and crucifers. BMC Evol. Biol. 7:243.

Sagi, M., and Fluhr, R. 2006. Production of reactive oxygen species by plant NADPH oxidases. Plant Physiol. 141:336-340.

Silipo, A., Molinaro, A., Sturiale, L., Dow, J. M., Erbs, G., Lanzetta, R., Newman, M.-A., and Parrilli, M. 2005. The elicitation of plant innate immunity by lipooligosaccharide of Xanthomonas campestris. J. Biol. Chem. 280:33660-33668.

Silipo, A., Erbs, G., Shinya, T., Dow, J. M., Parrilli, M., Lanzetta, R., Shibuya, N., Newman, M. A., and Molinaro, A. 2010. Glyco-conjugates as elicitors or suppressors of plant innate immunity. Glycobiology 20:406-419.

Sinha, D., Gupta, M. K., Patel, H. K., Ranjan, A., and Sonti, R. V. 2013. Cell wall degrading enzyme induced rice innate immune responses are suppressed by the type 3 secretion system effectors XopN, XopQ, XopX and XopZ of Xanthomonas oryzae pv. oryzae. PLoS One 8:e75867.

Sun, A., Nie, S., and Xing, D. 2012. Nitric oxide-mediated maintenance of redox homeostasis contributes to NPR1-dependent plant innate immunity triggered by lipopolysaccharides. Plant Physiol. 160:1081-1096.
Thimm, O., Bläsing, O., Gibon, Y., Nagel, A., Meyer, S., Krüger, P., Selbig, J., Müller, L. A., Rhee, S. Y., and Stitt, M. 2004. MAPMAN: A userdriven tool to display genomics data sets onto diagrams of metabolic pathways and other biological processes. Plant J. 37:914-939.

Torres, M. A., Jones, J. D., and Dangl, J. L. 2006. Reactive oxygen species signaling in response to pathogens. Plant Physiol. 141:373-378.

Vinagre, F., Vargas, C., Schwarcz, K., Cavalcante, J., Nogueira, E., Baldani, J., Ferreira, P., and Hemerly, A. 2006. SHR5: A novel plant receptor kinase involved in plant-N2-fixing endophytic bacteria association. J. Exp. Bot. 57:559-569.

Westphal, O., and Jann, K. 1965. Bacterial lipopolysaccharide extraction with phenol-water and further application of procedure. Methods Carbohydr. Chem. 1:83-89.

Yun, M. H., Torres, P. S., El Oirdi, M., Rigano, L. A., Gonzalez-Lamothe, R., Marano, M. R., Castagnaro, A. P., Dankert, M. A., Bouarab, K., and Vojnov, A. A. 2006. Xanthan induces plant susceptibility by suppressing callose deposition. Plant Physiol. 141:178-187.

Zeidler, D., Zähringer, U., Gerber, I., Dubery, I., Hartung, T., Bors, W., Hutzler, P., and Durner, J. 2004. Innate immunity in Arabidopsis thaliana: Lipopolysaccharides activate nitric oxide synthase (NOS) and induce defense genes. Proc. Natl. Acad. Sci. U.S.A. 101:15811-15816.

\section{AUTHOR-RECOMMENDED INTERNET RESOURCES}

agriGO database:

http://bioinfo.cau.edu.cn/agriGO/analysis.php?method=SAGE

ImageJ analysis tool: https://imagej.nih.gov/ij

Pathway Tools Omics Viewer webpage:

http://pathway.gramene.org/overviewsWeb/celOv.shtml

RiceCyc software: http://pathway.gramene.org/gramene/ricecyc.shtml 